the stomach and bowel to be operated on are in close apposition. The parts are surrounded with strips of gauze or flat swabs. An incision about one and a half inches in length is now made into the stomach and bowel through all the coats down to the mucosa, and then with a pair of ophthalmic scissors and forceps the coats all round are separated from the mucosa for a short distance, so that a broad surface of all these coats may be brought into contact. The posterior edge of the stomach incision is now stitched to its fall extent to a similar portion of the bowel with chromic

FIG. 1.

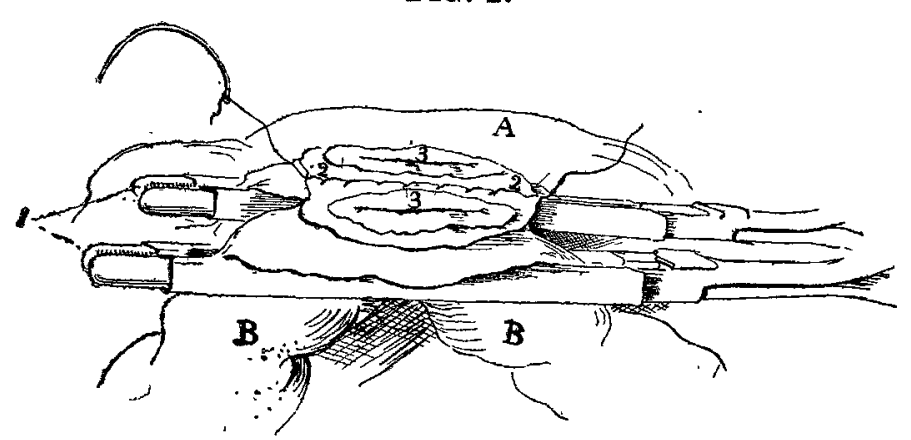

1. Doyen's forceps covered with rubber tubing clamping. A, Stomach. B, Jejunum. 2, Posterior edges of sero-

muscular coats united with continuous catgut suture.

gut by means of a small curved Hagedorn's needle, the suture is knotted at both ends, and left long (Fig. 1). An elliptical portion of the mucous membrane is now excised from the stomach and a similar portion from the bowel and the parts are cleansed. The cut edges of the mucous membranes are now stitched the whole way round by a continuous stitch of catgut, knotting it at the two extremities of the openings so as to prevent its drawing too tightly and narrowing the opening. This done the anterior edges of the incisions into the stomach and bowel through the remaining coats are united by a continuous stitch, the same suture which was left long after uniting the posterior edges (Fig. 2). I am

FIG. 2.

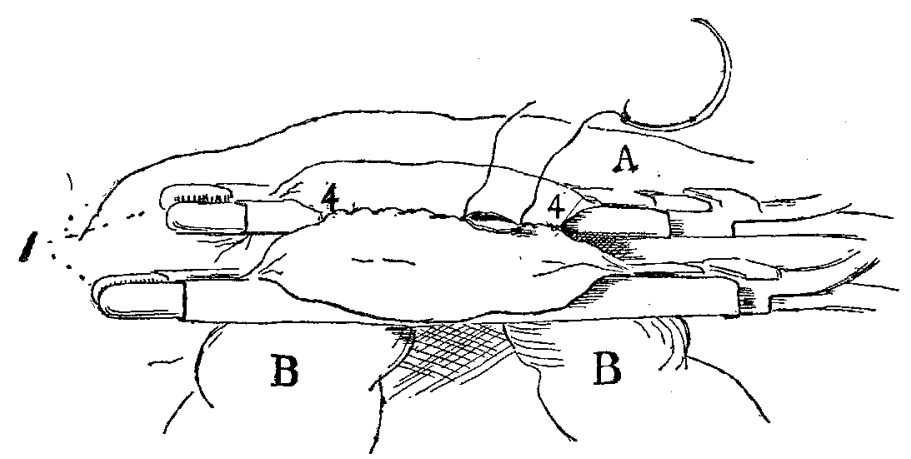

4, Anterior edges of sero-muscular coats united with a continuous catgut suture, the edges of the mucous coats having been sutured in a similar manner. $I$ and $A$ and $B$ refer as in Fig. 1.

not careful to bring serous coat to serous coat, but I rather prefer to bring the deeper layers into apposition. The clamps are then removed. As a rule there is no bleeding - the stitching prevents this. It is important not to pall the stitches too tightly. The gauze is removed and the abdomen is closed. The actual cutting and stitching can easily be done in from 10 to 15 minutes.

Enterectomy - In doing enterectomy I perform a very similar operation. The parts to be excised are clamped above and below with Doyen's clamps and are removed with scissors. A portion of mucous membrane is excised so that it retracts beyond the cat edges of the other coats. This leaves a good broad surface for stitching. The two cut ends are approximated by the clamps and they are then closed by continuous catgut stitches in the same way as for gastro. enterostomy. Half the lumen, consisting of all the coats with the exception of the mucosa, is first stitched and fastened, then the mucous membrane the whole way round, interrupting and knotting the stitches in two places, and finally the remainder of the coats are sutured. The clamps are removed and the cut surfaces of the mesentery are approximated by interrupted sutures. The long handles of the clamps enable them to be held in such a manner that the hands of the assistant are well away from the field of operation.

I am indebted to my late house surgeon, Mr. F. Talbot, for the drawings.

Leeds.

\section{A CASE OF ECTOPIC GESTATION WITH SEPTIC INFECTION OF THE GESTATION SAC. ${ }^{1}$}

BY H. MACNAUGHTON-JONES, M.D., M.A.O., F.R.O.S. IREL. \& EDIN.

A Patient, aged 30 years, was seen by me in consultation with Dr. Alexander McDonnell of Stamford-hill towards the end of March, 1901. She had been married nine years, her only pregnancy being one at the close of the first year. The periods had been normal and regular up to Nov. 24th, 1900. On different occasions she had been treated for retroversion and prolapse of the uterus. On Dec. 10th, 1900, she was attacked with violent abdominal pain which passed off but recurred on Jan. 10th, 1901. The catamenia appeared on Jan. 24th. On the 29th there was a recurrence of the severe pain, which lasted for three days, when she passed from the vagina what she described as "a yellowish pink substance somewhat like the roe of a mackerel." She remained in bed for a fortnight and on Feb. 10th was able to go out of doors. On the 25 th she was attacked with severe hæmorrhage, and again she passed portions of the same substance as before. Hæmorrhage and pain ceased until March 11th, when the former again recurred. On examination I found a fairly large tumour behind the uterus and associated with it, the uterine cavity being some two and three-quarter inches in length. Believing with Dr. McDonnell the case to be one of ectopic gesta. tion and having regard to the size of the mass and the presence of adhesions, abdominal coeliotomy was determined upon and the operation was performed on April 1st. The adhesions were separated with but little trouble, bat in the delivery of the sac through the enlarged abdominal incision a portion of the thin wall ruptured and some extremely foetid flaid escaped, creating at the time quite a stench. The pelvic cavity was repeatedly cleansed with weak formalin solntion, and as the bowel was well protected from the sac the only parts really affected, and this was unavoidable, were the margins of the wound. These latter were well wiped with 1 in 1000 of formalin before being closed, and an iodoform gauze drain was left in. There was nothing unusual in the course of the case for 48 hours, when the temperature rose to over $100^{\circ} \mathrm{F}$. and the patient commenced to vomit. This, however, was controlled by an effervescing mixture. Sulphate of magnesia and calomel were given, both being retained, but without any result. Still, the temperature did not again reach $100^{\circ}$, nor did the pulse exceed 96 up to the fourth day. In the afternoon of that day, as the abdomen was distended and there was no result with enemata, while the vomiting recurred and the countenance did not improve, the pulse reaching 110 , I determined to reopen the abdomen. On doing so I found the atonic bowel to be considerably distended but conld not detect any kink or cause for obstruction. The pelvic cavity was quite free from any flaid and there was no evidence of any peritonitis or of infection of the peritoneum, but the margins of the abdominal wound showed a dense slough for its entire extent. There had been no indication of this from the appearance of the incision. The patient had complained of lititle or no pain from the time of the operation. The slough at either side was cleared off as far as possible and a drainage tube was inserted. As I had to leave home the same night Mr. Targett kindly took charge of the case for me. The temperature fell the next day to normal, but again it rose to $100^{\circ}$ in the evening, the pulse becoming more rapid (from 120 to 140 ) with a return of the vomiting. Despite every means employed to combat the sickness and maintain her strength, including enemata, saline injections, washing out of the stomach, \&c., death occurred on the seventh day after operation.

1 A paper read before the British Gynæcological Society on June 13 th, 1901 . 
In this case the temperature never exceeded $100 \cdot 2^{\circ} \mathrm{F}$. and there was an absence of the usual symptoms of general peritonitis. Mr. Targett reported of the specimen that it consisted of the right uterine appendages and a gestation sac the latter being inclosed within the outer end of a dilated Tallopian tube :-

On section the wall of the gestation sac was found to be infiltrated with blood-clot and fibrin, as in a tubal mole. Where suppuration has occurred the placental tissue is separated from the inflamed tube by pus, and chorionic villi are in actual contact with the inflammatory products. The mucous membrane of the tube is destroyed and replaced by granulation tissue. The tumour is roughls spherical in shape and measures $8 \times 7 \times 6$ centimetres $\left(3 \frac{1}{4} \times 2 \frac{3}{4} \times 2 \frac{1}{4}\right.$ inches) in its chief diameters after fixation in formalin. A portion of the posterior wall of the mass has been removed and reveals two cavities. The larger of these is the gestation sac containing a foetus, while the smaller is a space formed between the gestation sac and the wall of the dilated Fallopian tube. In the recent state this latter space was filled with very offensive pus. Flattened out on the half of the tumour nearest to the uterus is the right ovary. The characters of the gestation sac are precisely those of an apoplectic or blighted ovum. It measures about five centimetres in its chief diameter, and its wall is composed largely of blood-clot in various stages of consolidation. The interior is lined with amnion which is unevenly raised by hæmorrhages beneath it A fotus measuring 2.75 centimetres is attached to the wall of the of the sac by an oedematous umbilical cord 175 centimetres in length, corresponding with the stage of development at the end of the second month. The suppurating cavity, semilunar in shape, represents that part of the dilated ampula of the tube not occupied by the gestation ended in a molar pregnancy or apoplectic ovum, and that secondary

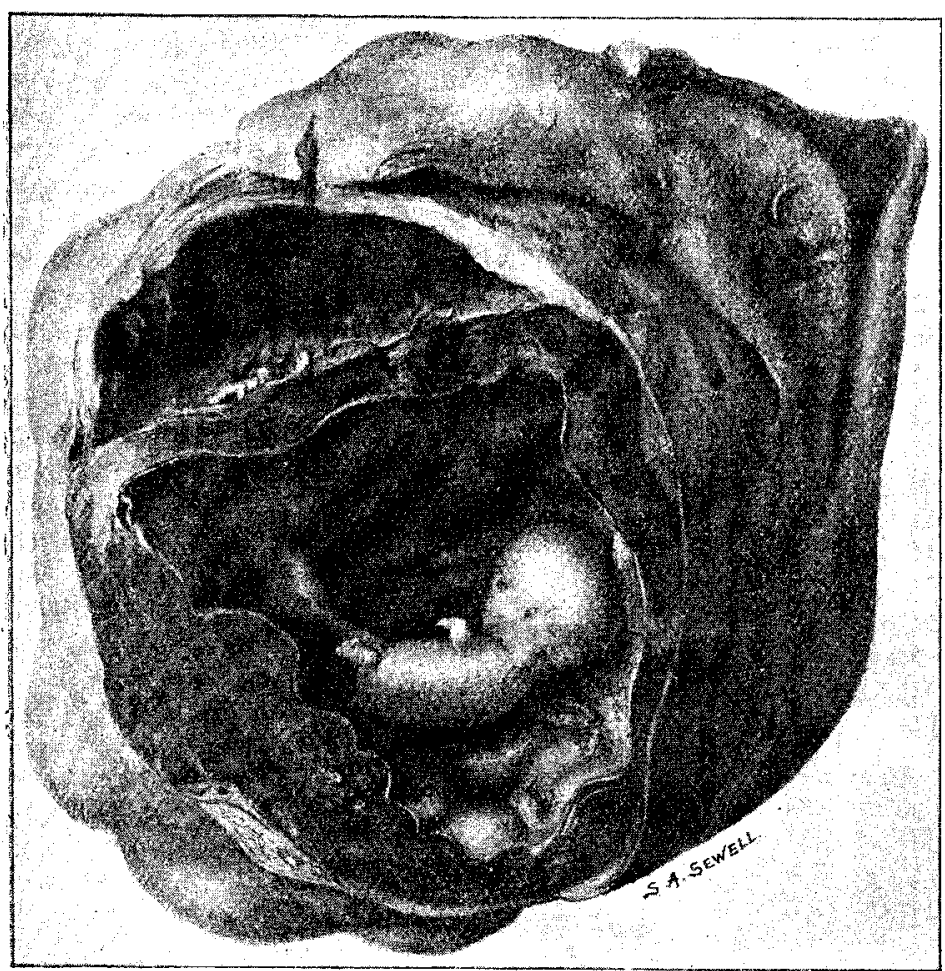

Gestation sac with fœetus; the upper cavity shown in the drawing is that in which the septic fluid was contained.

euppuration had been set up within the dilated tube and around the ovum. Consequently the pus had collected in that internal cavity at only one spot upon the wall of the dilated tube.

It would seem that the source of infection must have been through the adherent bowel. The patient having suffered from retroversion of the uterus the early symptoms might naturally lead to the impression that it was an enlarged retroverted and gravid uterus and tend to make the diagnosis less certain. From the size of the tumour and the impression which it conveyed of fixation by adhesions I determined on the abdominal operation, though, as events proved, considering the nature of the sac, the vaginal one would have been the safest one for the patient. Had I a similar case again, with rupture of a fotid sac, having protected the bowel I should first char the margins of the abdominal wound with the thermo-cautery, and then at some distance from the charred surfaces make a new incision at either side before closing the wound. Not long since I opened the abdomen for a large and very fotid subperitoneal abscess which had penetrated the peritoneum. Having evacuated the pus and thoroughly cleansed out the abdominal cavity with formalin, disinfecting the edges of the wound, which were covered by a foul and deep slough, I removed this at either side before bringing the edges together and drained. Contrary to my expectation the patient made an excellent recovery.

Harley-street, $W$

\section{ARE NOT SOME PATIENTS SAID TO BE AFFLICTED WITH GASTRIC ULCER \\ REALLY SUFFERING FROM A DIFFERENT DISEASE?}

BY W. HALE WHITE, M.D., F.R.C.P. LOND., PEYSICIAN TO, AND LEOTURER ON MEDICINE AT, GUY'B HOBPITAL.

IT is allowed that the malady commonly diagnosed as gastric ulcer is very much more common in women than in men; also that many more cases in women occur in the two decades from 20 to 40 than in any other two decades, whilst in men the disease is commoner later in life. Further, the mortality in men is higher than in women. For instance, Dr. R. Saundby has stated ${ }^{1}$ that among 15 deaths at the Birmingham General Hospital due to gastric ulcer 11 occurred in men and four in women, a striking contrast when we remem. ber the greater frequency of the diagnosis of gastric ulcer in women. Because of these facts I have for years been accustomed to teach that one of two conclusions must follow : either the outlook of gastric alcer in women is much more favourable than it is in men, or many cases occurring in women and classified as gastric ulcer at the bedside are really instances of some other undescribed malady. I have also maintained that the second is the more likely view, for it relieves us of the difficulty of explaining the otherwise obscure facts that so-called gastric ulcer is at its maximum frequency earlier in women than in men and is commoner in women than in men, although actually more fatal in men, and this view renders it more easy to understand why the condition diagnosed as gastric ulcer is so frequently associated with chlorosis, for this disease is almost confined to women and is met with at about the same time of life as that at which the diagnosis of gastrio ulcer is most frequently made. I have therefore often suggested that there is a disease met with chiefly, or perhaps only, in women usually between 20 and 40 years old; that its chief symptoms are gastric pain, nausea, sickness, and hæmatemesis, that these symptoms are not dependent upon ulceration of the stomach, any ulceration that may be present being quite superficial and no more than might occur secondarily to the hæmorrhage; and that the diagnosis from genuine gastric ulcer occurring in women is very difficult, yet the facts that in spite of serious gastric symptoms extending over years the patient is not wasted, has been or is often chlorotic, and has none of the mechanical effects of gastric ulcer, such as adhesions, pyloric stenosis, or subphrenic abscess, may help us to a right conclusion.

The prognosis is entirely different from that of gastrio ulcer, for, apart from hæmorrhage, these patients are not liable to the numerous serious complications of gastric ulcer. The prognosis is good, although relapses are frequent. Occasionally, but excessively rarely, the sufferers may die from hæmorrhage, and then no cause for it is found. The disease is in many cases, I apprehend, closely related to chlorosis, for it certainly is often associated with it or occurs in those who have formerly suffered from chlorosis, but it may, I think, exist apart from chlorosis. Until we know something of the cause of chlorosis we can hardly hope to know what the association is. I have not hitherto liked to put this view on paper for want of direct evidence in its favour, but now that surgeons have taken to opening the stomach for severe bleeding some support is fortheoming. Operators are already accustomed not to find an ulcer even when the hæmorrhage has been severe. Thus Mayo Robson * says: "If no ulcer be found anywhere and the bleeding proves to be capillary or from small undiscoverable ulcers." I take it that here we may assume that if the ulcer proves to be undiscoverable no ulcer exists. My proposition seems also to be supported by the following quotation from Mayo Robson" " "Erosions.-Of these Dieulafoy has described two varieties: (a) simple erosions, consisting apparently of mere abrasions of the surface

1 Brit. Med. Jour., vol. 11., 1900, p. 1613.

3 Brit. Med. Jour., Feb. 2nd, 1901, p. 257 